\section{What Motivates Biology Instructors to Engage and Persist in Teaching Professional Development?}

\author{
Jill S. McCourt, ${ }^{\dagger}$ Tessa C. Andrews, ${ }^{\ddagger}$ Jennifer K. Knight, ${ }^{\S}$ John E. Merrill," \\ Ross H. Nehm, Karen N. Pelletreau, ${ }^{*}$ Luanna B. Prevost, ${ }^{\circledR}$ Michelle K. Smith, ${ }^{\#}$ \\ Mark Urban-Lurain,** and Paula P. Lemons ${ }^{\dagger *}$ \\ ${ }^{\dagger}$ Department of Biochemistry and Molecular Biology and "Department of Genetics, University of \\ Georgia, Athens, GA 30602; \$Department of Molecular, Cellular, and Developmental Biology, \\ University of Colorado, Boulder, CO 80309; "Department of Microbiology and Molecular Genetics \\ and ${ }^{* *}$ College of Engineering, Michigan State University, East Lansing, MI 48824; "Department of \\ Ecology and Evolution, Stony Brook University (SUNY), Stony Brook, NY 11794; \#School of Biology \\ and Ecology, University of Maine, Orono, ME 04469; ‘ Department of Integrative Biology, \\ University of South Florida, Tampa, FL 33620
}

\begin{abstract}
We conducted a study of 19 biology instructors participating in small, local groups at six research-intensive universities connected to the Automated Analysis of Constructed Response (AACR) project (www.msu.edu/ aacr). Our aim was to uncover participants' motivation to persist in a long-term teaching professional development effort, a topic that is understudied in discipline-based educational research. We interviewed each participant twice over a 2-year period and conducted qualitative analyses on the data, using expectancy-value theory as a framework for considering motivation. Our analyses revealed that motivation among instructors was high due to their enjoyment of the AACR groups. The high level of motivation is further explained by the fact that AACR groups facilitated instructor involvement with the larger AACR project. We also found that group dynamics encouraged persistence; instructors thought they might never talk with colleagues about teaching in the absence of AACR groups; and groups were perceived to have a low-enough time requirement to warrant sustained involvement. We conclude that instructors have persisted in AACR groups because the groups provided great value with limited cost. The characterization of instructor experiences described here can contribute to a better understanding of faculty needs in teaching professional development.
\end{abstract}

\section{INTRODUCTION}

Undergraduate biology education is at a critical juncture. With calls for reform from organizations including the American Associate of the Advancement for Science (AAAS), the National Research Council (NRC), and the President's Council of Advisors on Science and Technology (PCAST), leaders in biology education recognize that current educational outcomes will not meet the growing need for science, technology, engineering, and mathematics (STEM) professionals (NRC, 2003; AAAS, 2011; PCAST, 2012). Undergraduate biology education classrooms can be improved when instructors use more active learning, which can be defined as pedagogies that require students to engage directly in and take responsibility for their own learning (Handelsman et al., 2007). In practice, active learning occurs when instructors stop lecturing and provide time for students to complete activities that build conceptual understanding. To facilitate active learning, instructors must assess student thinking, which includes a mixture of scientific and nonscientific ideas, and use these data to modify instruction. Research has repeatedly shown that incorporating active-learning strategies into the classroom can be an effective way to increase student competence and retention, especially
Deborah Allen, Monitoring Editor Submitted August 5, 2016; Revised May 18, 2017; Accepted June 13, 2017

CBE Life Sci Educ September 1, 2017 16:ar54 DOI:10.1187/cbe.16-08-0241

*Address correspondence to: Paula P. Lemons (plemons(auga.edu).

(c) 2017 J. S. McCourt et al. CBE-Life Sciences Education @ 2017 The American Society for Cell Biology. This article is distributed by The American Society for Cell Biology under license from the author(s). It is available to the public under an Attribution-Noncommercial-Share Alike 3.0 Unported Creative Commons License (http:// creativecommons.org/licenses/by-nc-sa/3.0) "ASCB $® "$ " and "The American Society for Cell Biology ${ }^{\circledR}$ " are registered trademarks of The American Society for Cell Biology 
among underrepresented groups (Eddy and Hogan, 2014; Freeman et al., 2014). Yet, the majority of STEM instructors still rely on lecture as their primary means of teaching and neglect the use of assessment data to inform teaching decisions (NRC, 2012). Clearly, evidence alone has not been sufficient to instigate widespread change in the college biology classroom.

Instructors must overcome many barriers if they are to change their teaching, and they must remain motivated to do so throughout the sometimes arduous change process. Instructors commonly say "we teach the way we were taught," and although this is an oversimplification, past experience in the classroom does shape the way many instructors approach teaching (Oleson and Hora, 2014). Many postsecondary instructors lack sufficient training in active learning, leading to a lack of confidence in their ability to successfully implement such strategies (Rushin et al., 1997; Handelsman et al., 2007). Compounding the problem is the issue that instructors may overreport their use of active learning (Ebert-May et al., 2011) or may implement such strategies poorly, leading to minimal or no apparent improvement in student learning (Andrews et al., 2011). Other barriers to change can come from institutional or departmental culture. If tenure is determined entirely by research success, or if there is a general lack of reward within the department for successfully improving one's teaching, it follows that many instructors may not devote the time necessary to make major changes in their teaching approaches (Hannan, 2005; Porter et al., 2006). Some instructors who have attempted active learning reported being discouraged when students were highly resistant to engaging with one another in the classroom (Dancy and Henderson, 2007). Finally, instructors often report that lack of time is another barrier, and many perceive that preparing an active-learning course takes substantially more time than preparing a traditional lecture course (Krockover et al., 2002; Howland and Wedman, 2004; Pundak and Rozner, 2007).

Change agents who want to support instructors in adopting active-learning approaches often have relied on the development and dissemination of teaching materials and assessments (Henderson et al., 2011). This change strategy works for getting alternative techniques and activities to instructors, but it is not sufficient for promoting sustained change (Penberthy and Millar, 2002; Clark et al., 2004). Rather, efforts to promote change are most productive when they involve extensive, longterm support (Gibbs and Coffey, 2004; Gallos et al., 2005; McShannon et al., 2006). Another hallmark of successful change strategies is performance evaluation and feedback (for a review, see Fixsen et al., 2005), and a third component includes helping instructors uncover and reconsider their conceptions of teaching and learning. Change strategies may be most successful if they deliberately encourage instructors to reflect on their teaching (Weiss et al., 2003).

One form of teaching professional development that incorporates long-term support, feedback, and reflection is the faculty learning community (FLC). Cox pioneered the FLC approach at Miami University using student learning communities as a model (Cox, 2001, 2003, 2004). He and his colleagues defined an FLC as "a cross-disciplinary faculty and staff group of six to fifteen members ... who engage in an active, collaborative, yearlong program with a curriculum about enhancing teaching and learning and with frequent seminars and activities that provide learning, development, the scholarship of teaching, and community building" (Cox, 2004, p. 8). The emphasis an FLC places on extended contact and ongoing learning is what makes it different from other workshop-like professional development activities (Walczyk and Ramsey, 2003; Davidovitch and Soen, 2006). The FLC model has been adopted widely, with different emphases. One common type of FLC focuses on providing pretenured faculty with teaching support (e.g., see Marbach-Ad et al., 2013). Another type, prevalent among biologists, is for course redesign with a focus on incorporation of active-learning strategies (Sirum and Madigan, 2010; Addis et al., 2013; Elliott et al., 2016). The positive impact of FLCs on teaching and learning has been demonstrated, primarily through self-reported participant surveys. According to these studies, participants report that FLCs enable them to make teaching improvements that impact student outcomes (LyndBalta et al., 2006; Beach and Cox, 2009) and change their perspectives on teaching and learning (Beach and Cox, 2009).

We used an approach to teaching professional development inspired by the FLC model to facilitate instructor use of teaching resources provided by the Automated Analysis of Constructed Response (AACR) project (www.msu.edu/ aacr; Ha et al., 2011; Haudek et al., 2011, 2012; Urban-Lurain et al., 2014; Weston et al., 2015; Prevost et al., 2016). AACR provides instructors with a library of 116 constructed-response questions about biology, including 96 evolution questions (Moharreri et al., 2014) and 20 questions on various other topics (Haudek et al., 2011). For each question, computer-automated analysis routines have been developed to predict expert ratings of the responses. Instructors who use AACR items submit their students' written responses for analysis, and a computer-generated report that categorizes students' ideas, including scientific and naïve conceptions, is automatically generated within minutes. Instructors can access these reports, learn how students in their courses answered the questions, and modify their teaching to address student conceptions. Thus, AACR questions provide instructors with the ability to efficiently gain insights into student thinking that are richer than the insights provided by most multiple-choice questions (e.g., Nehm and Schonfeld, 2008).

We suspected that instructors would need support in order to incorporate AACR assessments and reports into their teaching tool kits, so we created FLC-like groups of instructors to provide teaching professional development. These groups were longterm, providing instructors with feedback from assessments of student thinking and creating the opportunity for instructors to reflect on their conceptions of teaching and learning through ongoing colleague-colleague discussions. We did not adopt all structural features of FLCs as defined by Cox (2004). Specifically, our instructor groups ranged in size from two to five members, which is smaller than the communities described by Cox (2004). Our meetings were less frequent than a traditional FLC, occurring approximately three times per semester. Finally, our members were all biologists, so our groups cannot be described as interdisciplinary. Thus, we simply refer to our local communities of instructors as AACR groups. We report here our investigation of AACR group members' motivation to participate and persist in teaching professional development.

Only a limited literature base exists that examines college instructors' motivations to engage and persist in teaching professional development (Stenfors-Hayes et al., 2010; BouwmaGearhart, 2012a,b; Sabagh and Saroyan, 2014). In recognition 
of this deficit, Bouwma-Gearhart investigated the experiences of STEM instructors at an R1 institution who had engaged in a program that included activities ranging from periodic dinner conversations to semester-long courses on pedagogy (BouwmaGearhart, 2012a). Through surveys and interviews, BouwmaGearhart found that instructors initially chose to participate due to factors such as departmental requirements, the desire to interact with others about teaching, and feelings of incompetence with respect to teaching (Bouwma-Gearhart, 2012a). BouwmaGearhart hypothesized that instructors initially seek out teaching professional development due to external factors, but intrinsic motivation is critical for persistence. To the best of our knowledge, only Bouwma-Gearhart has studied motivation among STEM instructors who actually engaged in teaching professional development; others have investigated potential motivation for teaching professional development among a broad sample of STEM instructors who may or may not have engaged in teaching professional development (Stenfors-Hayes et al., 2010; Sabagh and Saroyan, 2014).

To build upon the work of Bouwma-Gearhart (2012a) in the context of AACR groups, we used expectancy-value theory (EVT), a framework for considering what motivates humans to engage and persist in certain behaviors. The development of EVT arose from the initial work of John Atkinson and colleagues (McClelland et al., 1954). At the center of this framework is the relationship between expectancy and value (Atkinson, 1957; Nagengast et al., 2011; Figure 1). Expectancy consists of the belief an individual has about whether or not he or she can succeed and the relative ease of the task at hand (Eccles, 1983, 2005; Eccles et al., 1984; Wigfield and Eccles, 1992, 2000). Value consists of four subcategories: attainment, intrinsic, utility, and cost. Attainment value refers to the importance one attaches to doing well at the activity and addresses how well a task aligns with an individual's personal identity (Battle, 1965, 1966; Eccles, 1983, 2005). That is, tasks that have high attainment value give an individual a chance to act out an important aspect of the central self. Intrinsic value addresses an individual's personal interest in the task (Deci and Ryan, 1985). If an individual enjoys participating in a task, or even expects to enjoy participating, the task is said to have high intrinsic value. Utility value describes the direct benefit an individual receives for participating. Finally,

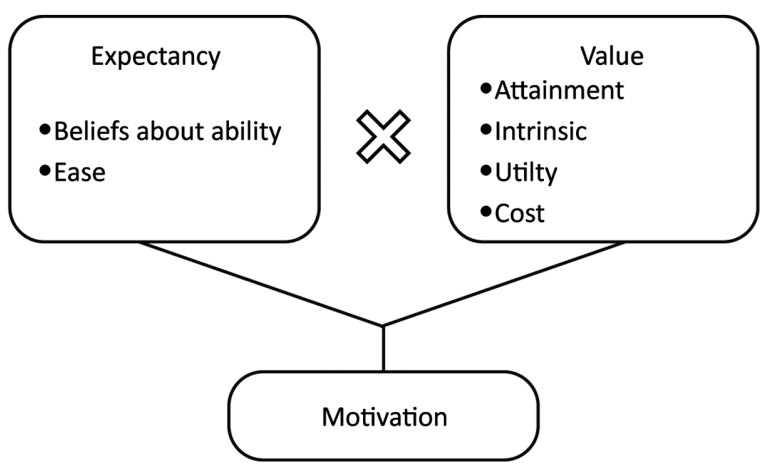

FIGURE 1. Expectancy-value theory. This traditional model of EVT details the relationship between expectancy, value, and the subcategories within each parameter. Modified from Finelli et al. (2014). cost is the subcategory of value that describes the amount of perceived sacrifice involved in carrying out an activity.

EVT was first applied to education to explain middle school girls' choice to pursue and persist in advanced mathematics courses (Eccles et al., 1984). The framework was later expanded to engineering education research. Matusovich and colleagues used EVT to investigate researchers' and practitioners' engagement with the research-practice cycle (Matusovich et al., 2014), and Finelli and colleagues used EVT to aid in understanding how faculty change their teaching practices to adopt more evidence-based methods (Finelli et al., 2014). Findings from the latter study were used to launch a faculty action plan based on the factors motivating instructors at their particular institutions (Finelli and Millunchick, 2013).

We used EVT to explore the primary motivation for instructors to participate and ultimately persist in AACR groups. This article follows 19 instructors who participated in six different AACR groups at six research 1 (R1) institutions for 2.5 years. We report our exploration of the reasons underlying this high level of persistence. Because little is known about instructor motivation for teaching professional development, we used qualitative methods to uncover rich descriptions, pulling data directly from the words of the participants.

\section{METHODS}

\section{Context and Participants}

This article focuses on a longitudinal in-depth analysis of 19 instructors during the first 2.5 years of a 5 -year study. These instructors participated in faculty groups created to support the adoption and sustained use of assessment tools developed by AACR, that is, AACR groups. Since January 2014, AACR groups at six different research institutions have been meeting three times per semester for 1 hour each meeting to learn about AACR and how to use AACR assessments and reports in their courses (Figure 2). Facilitators from the AACR project recruited participants at their own institutions. The number of participants at each university ranges from two to five. All AACR groups have the support of local administrators, and some administrators are project participants themselves (Figure 3). Participants agreed to attend local meetings, to respond to online surveys, and to be interviewed once per year. In addition to regular, local meetings, 14 participants attended a 2-day, in-person meeting in May 2014 that included all facilitators and research team members (Figure 2). Participants received $\$ 1500$ for completing surveys and research interviews each year. The University of Georgia Institutional Review Board approved this study under exempt status (Study 00000257).

AACR group meetings vary in their content based on the institution, timing (i.e., year 1 or 2), and at which point in the semester the meetings occurred. AACR questions and reports provide evidence to support the prevalence of known conceptual difficulties among students and have uncovered additional ways that students think about challenging biology concepts (Haudek et al., 2012; Weston et al., 2015; Prevost et al., 2016). Thus, AACR group meetings consist of discussions about how to use AACR questions and interpret reports, the types of student ideas revealed in the reports, and how to address common student misconceptions. The first meeting of the semester often focuses on logistics, such as when instructors will ask AACR questions in their classrooms. Later in the semester, discussions 


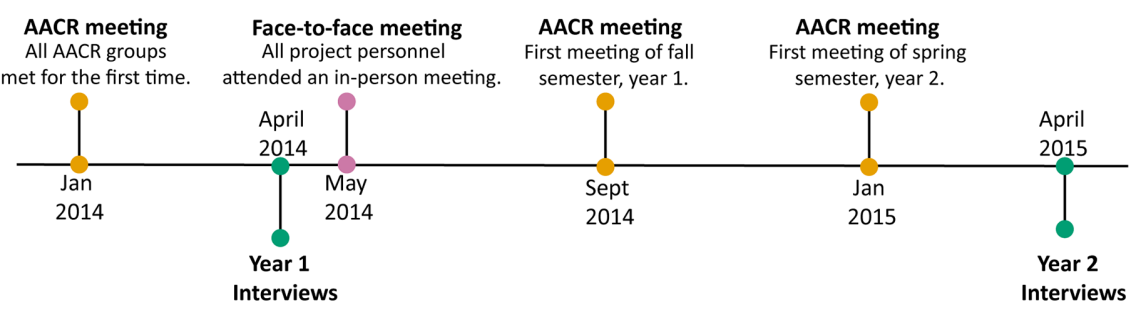

FIGURE 2. Project timeline. AACR groups met three times per semester beginning in January 2014. For simplification, only the first AACR group meeting of each semester is indicated. In May of 2014, 14 participants attended a face-to-face meeting along with all facilitators and researchers. The semistructured interviews were conducted yearly, beginning in April 2014 and April 2015.

often shift toward AACR reports and student ideas. As time has progressed in the project, discussions of the reports have taken up less time, leaving more time for general discussions about teaching and how to address the student misconceptions revealed in the AACR reports (unpublished data).

\section{Data Collection}

We interviewed AACR group participants two times during the first 2.5 years of the project. To probe instructors' perceptions of the local AACR groups, we used semistructured interviews. The interviewer used a list of predetermined questions, but also used follow-up questions to learn more about interviewees'



FIGURE 3. Structure of the AACR groups. Local AACR groups (white circles) met at six research-intensive institutions (large light blue circles). The facilitators (small dark blue circles) led meetings attended by instructors (orange), some of whom have administrative roles (green). Committed administrators who offered support but did not participate in the FLCs are depicted outside the white circles. Instructors were also invited to participate in a cross-institutional virtual community of practice. ideas (Patton, 2014). One author (J.S.M.) conducted all interviews. She was a postdoctoral associate who did not serve as an AACR group facilitator and did not attend any of the AACR group meetings.

The year 1 interviews began in April 2014 (Figure 2). This interview script covered a range of topics (Supplemental Interview Script Year 1). Most salient to the themes addressed in this article, the interviewer asked questions to uncover participants' reasons for agreeing to participate in the project and their anticipated benefits from the AACR group. The year 2 interviews began in April 2015 (Figure 2). We generated questions for year 2 interviews by examining both EVT and the anticipated benefits identified in the first interviews. For example, preliminary analyses of year 1 interviews revealed that all participants were highly motivated to join the AACR group simply because they had been asked by a respected colleague. Thus, in the year 2 interviews, we focused on factors that motivated members to persist in the AACR groups, in addition to other topics (Supplemental Interview Script Year 2).

Our interview protocol was informed by literature on faculty professional development and motivation to participate. We were interested in generating hypotheses about the underlying reasons for persistence in the AACR project, using the existing literature to guide our investigation. Before each year 1 interview, the script was tailored individually for each participant in light of survey responses. Specifically, we reviewed the instructors' responses to a survey about their professional development experiences, perceptions of AACR questions and reports, and expectations for the AACR project. We then modified the interview script on the basis of individuals' survey responses. For the year 2 interviews, we customized each script by reviewing the previous interview. For example, in the April 2014 interviews, each participant offered one way he or she would try to address a problem encountered in teaching a course. In year 2 interviews, we probed with questions concerning how well the proposed solution had worked, or whether it had been attempted.

\section{Data Analysis}

During and immediately following each interview, J.S.M. took notes to form initial impressions and look for emerging patterns. Each interview was transcribed verbatim and checked for accuracy against the interview recordings. Two members of the research team (P.P.L. and J.S.M.) began the analysis by open coding (also called "initial coding") the year 1 interviews (Strauss and Corbin, 1998; Saldaña, 2013). Although we had not 
TABLE 1. Perceived value of the AACR groups

\begin{tabular}{ll}
\hline Category & Number of \\
Illustrative quote & participants \\
\hline
\end{tabular}

AACR groups facilitate instructor involvement with AACR

AACR groups help instructors use AACR questions and interpret reports.

AACR groups enable instructors to contribute to education research associated with AACR.

AACR groups help instructors feel connected to the project.
Also, debriefing the reports is helpful too, but it was more helpful for me in terms of just becoming ... just being introduced to the reports, since I hadn't really seen them before and didn't know how they worked. (Samantha)

And I wanted to get involved in a science education effort. (Hannah)

I do appreciate being able to link up with the other AACR folks here on campus. (Jeff)
18

Then [AACR colleague] being part of it, I think, is great because as an administrator, he's not teaching these particular large classes, but he certainly cares about them a lot. So I was really glad that he was involved in it. (Laura)

Without the AACR group instructors might never talk with colleagues about teaching

AACR groups help instructors feel like they are not alone in facing teaching challenges.

AACR groups provides a place to discuss a specific course.

Instructors get ideas for classroom activities during FLC meetings.
Sometimes you put all this effort in and then it doesn't help [students], so learning that I'm not the only one that feels that way helps me and keeps me motivated in terms of continuing to try to improve my course and my teaching. (Samantha)

Well a lot of the other faculty also teach the [same course], so just talking with them about what they're doing in their courses and sharing that kind of information I think is really beneficial. (Kyle)

What I get most out of it is the discussions about in-class exercises and ideas for doing active-learning things in the classroom. (Andrew)

I thought [the AACR group] sounded interesting, and it didn't seem as though it was going to be labor intensive. So I agreed to do it. (Liz)

Instructors worry about spending time participating in teaching professional development

identified a priori codes or themes, we knew we were looking to explain the phenomenon of motivation and persistence. Thus, we carefully went through each interview, identifying the sections pertaining to motivation. After marking the appropriate excerpts, we worked to create a codebook using the words of the participants, a process called in vivo coding (Charmaz, 2006; Saldaña, 2013). As we analyzed data from subsequent interviews, we used the method of constant comparison; that is, as we analyzed data from one interview, and we compared ideas with our working codebook (Glaser and Strauss, 1967; Schwandt, 2007). As new codes emerged, we analyzed previous interviews again to look for the new codes. We continued this iterative coding process until no new codes were revealed in the data (Charmaz, 2006; Saldaña, 2013). We maintained this process for the year 2 interviews, working to refine and eliminate redundant codes and continuing until no new ideas emerged from the complete data set. Once we were satisfied that our codebook for the year 1 and 2 interviews was complete, we identified major themes across codes, using EVT to view our results from a theoretical perspective. As reported in this article, a major theme provides explanation for distinct aspects of the overarching finding. Themes are composed of multiple subcategories; subcategories are collections of codes that are related (see Table 1). We counted the occurrence of themes or subcategories within themes. If a transcript contained multiple instances of a subcategory for the same participant, we only counted it one time for that participant. All coding was completed in MAXQDA, versions 11 and 12 .

We do not refer to our process as using grounded theory, because our aim was not to develop a novel theoretical framework with respect to motivation. Instead, we sought to understand the participants' experiences, and interpret their descriptions in order to provide some explanation for why instructors persist in teaching professional development through the AACR project (Glaser and Strauss, 1967; Strauss and Corbin, 1998; Suddaby, 2006; Saldaña, 2013).

\section{RESULTS}

We present our major themes here using quotes taken from the semistructured interviews with participants. Whenever possible, we present instructor's quotes exactly as stated. However, some quotes have been lightly edited for clarity. Any changes to 
the original quotes are indicated with brackets or ellipses. All quotes are credited using pseudonyms.

One overarching theme characterizes the entire data set: instructors have enjoyed the AACR groups and intend to continue participating. Instructors stated that they considered the meetings useful and even fun. Moreover, they reported that participation in an AACR faculty group was easy; it did not take too much time, and meetings accommodated their schedules. We observed this theme in year 1 interviews, but the nature and prevalence of the theme was more explicit in year 2 interviews.

In year 1 interviews, instructors expressed that they liked the AACR meetings, but they also expressed uncertainty about the project. Consider Jessica's reluctance to commit to how much impact the AACR faculty group meetings would have on her teaching:

Interviewer: So in the survey, you said you were unsure of the impact the [AACR group] would have on your teaching, so has this changed at all since you've had a couple of meetings or are you still really not sure?

Jessica: Yeah. I mean in the end, it's really hard to knowagain, [what is] a real impact. I like what [my colleague] showed me, but if I can't ever incorporate it into my class because it's just not physically feasible then-you see what I mean?

In year 2 interviews, instructors still said they liked the AACR groups, and we detected very little uncertainty about the impact of the groups. Instead, participants enthusiastically expressed their intent to continue, because they perceived the meetings as valuable and enjoyable. When we directly asked Laura how likely it was that she would continue to participate in the project, she said the following:

Laura: Oh, yeah, very likely.

Interviewer: What makes you say that?

Laura: I enjoy the group. I like what I get out of it. I feel like my input is appreciated.

In the following sections, we present the four major themes from our data that explain the overarching finding that instructors' have enjoyed the AACR groups and are experiencing high motivation to persist. Table 1 provides a summary of these themes, which include the following:

- AACR groups facilitated instructor involvement with the AACR project.

- AACR group dynamics encouraged persistence.

- Without AACR groups instructors might never talk with colleagues about teaching.

- Instructors worry about spending time participating in teaching professional development.

\section{AACR Groups Facilitate Instructor Involvement with the AACR Project}

One recurring theme was that AACR groups facilitated instructors' use of AACR questions and reports and contributed to the overall connectedness in the project. The AACR groups were meeting separately at multiple institutions, and the chance to meet with other local faculty, as well as the facilitator (who was also a principal investigator [PI] on the project), contributed to the overall connectedness instructors felt to the AACR project. Within this major theme, we identified the following subcategories: 1) AACR group meetings help instructors use AACR questions and interpret reports, 2) participation enables instructors to contribute to education research associated with AACR, and 3) AACR groups help instructors feel connected to the project.

AACR groups were designed to support instructors in their use of the AACR questions and reports. Before the meetings, most instructors had never asked an AACR question or viewed an AACR report. For that reason, during the first two semesters of the project, meeting time largely was spent discussing AACR questions and how the analytic tools and reports are generated. We found that instructors credited the group meetings as important for learning how to use AACR questions and reports and that most would have been unlikely to ask AACR questions or even attempt to read reports without meeting with their groups (Table 1). Additionally, instructors reported that the meetings gave them an opportunity to contribute to the research of their facilitators (the local PIs; Table 1) and increased their sense of connectedness to the project as a whole (Table 1).

\section{AACR Group Meetings Help Instructors Use AACR Questions} and Interpret Reports. The AACR library consists of more than 100 biology questions in areas such as evolution, structurefunction, and information flow. To successfully use AACR questions, an instructor must select questions; administer questions to students, normally as homework via their online course management system; collect and deidentify student data; send the student data for analysis; receive a report; and interpret the report to learn about student models of thinking about the question. AACR reports are not immediately intuitive to instructors. The reports present models of student thinking much differently than a standard exam key, and they provide instructors with a tremendous amount of data (Haudek et al., 2011, 2012). Given the multistep, complex process required for using AACR, we were unsurprised to find that most instructors felt they needed the support of the AACR group to be successful. In year 1 interviews, these views were especially prevalent. Josh noted how difficult it would have been to navigate using AACR on his own without support:

Josh: I mean it's obviously been really critical for us to have the [AACR group] to be able to go through [an AACR report] and understand it, because it's not intuitive, which I don't think is a bad thing at all because the information that is in there is really valuable. But it's helpful to have somebody walk you through it a couple of times.

Allison explained that, without the AACR group, she would not have thought deeply about the reports or what she could learn from them:

Allison: Having those [AACR group] meetings prompted me to really ask myself what's most useful [about the AACR reports]. How am I going to use this? Because at first I just said, "Sure, I'll do this." And I didn't [give] it much more thought. I just set up an assignment and did it. 
Liz reported that, without the AACR group, she would not have used AACR at all:

Interviewer: So, do you feel like meeting with the group is helping you use the AACR questions successfully in your classroom?

Liz: I've only [asked an AACR question] once... Just once. If I didn't have the group, I would have done it zero times, so yes.

AACR groups were clearly important for the participants' success in using AACR during year 1. In the Fall of 2014, nearly all instructors responded positively to survey questions asking about their ability to interpret AACR reports and understand how data for the reports are generated. Therefore, we did not probe this topic further in year 2 interviews.

Participation Enables Instructors to Contribute to Education Research Associated with AACR. All of the AACR group facilitators conduct education research related to the AACR project and lead other education research efforts. In our analysis of year 1 interviews, we found evidence that some participants were motivated to participate in AACR groups in order to engage in education research. Consider Josh's statement concerning his colleague's research:

Josh: [AACR is] also one of the ways that all of us are plugging into [facilitator's] research program. That will continue to happen in ways that are non-AACR too.

Likewise, Hannah saw the AACR project as a way to contribute to the goal of improving a course based on information from education research:

Hannah: Well, I learned about it from [facilitator] who sent a general email to the [Introductory Biology] instructors, and I teach the course three times a year. So I'm very familiar with the strengths and the weaknesses of the course, and I wanted to get involved in a science education effort.

Jeff, who has a teaching-only appointment, viewed the AACR group as a way to participate in research focused on improving student learning, which is the goal of AACR research:

Jeff: I'm really interested in knowing how best to help students, and I find that I'm 100\% instruction, and I do also like to do research. But this is one way I can do research on a topic that I like with some other people who don't always necessarily think the same way I do, but we're all working toward a common goal of helping students out. I plug into this research network that I couldn't otherwise.

AACR Groups Help Instructors Feel Connected to the Project. Despite the large number of items in the AACR database, not all biological topics are represented. For this reason and due to varying teaching assignments, not all participants found the topics of AACR questions to be relevant to their courses every semester. However, we asked instructors to participate in the AACR groups each semester, regardless of whether they could use an AACR question or were teaching. Several participants credited this ongoing group meeting participation with helping them stay connected to the project, even if they were not directly using AACR at the time. Tim was assigned to teach a different course one semester that did not overlap with any AACR question content. He credited the group meetings with keeping him in the project:

Tim: Especially for me since I'm not actively using [AACR questions] right now, [the AACR group] keeps me a little bit in the loop without totally forgetting and coming back and being like, "What was this about again?"

\section{AACR Group Dynamics Encourage Persistence}

All participants in our study reported that the value of the AACR group related to the specific individuals in the group. Most instructors reported that they initially decided to get involved in the AACR project because they were asked by the facilitator, whom they respected (Table 1). Instructors also reported that they get along well with their colleagues, and this rapport directly contributed to their enjoyment of AACR group meetings (Table 1). The identities and personalities of the group members were often cited as a reason for enjoying the meetings. Finally, at some institutions, administrators participate in AACR groups, and instructors reported that they appreciate the opportunity to learn how their administrators are thinking about teaching and learning (Table 1). Within this major theme exploring group dynamics, we found the following subcategories: 1) instructors agreed to participate because they respect their facilitators, 2) AACR group meetings provide a sense of camaraderie, and 3) administrators add value to AACR groups.

Instructors Agreed to Participate Because They Respect Their Facilitators. The AACR group facilitator at each institution is the point person for all meetings and for the AACR project in general, assisting instructors in all aspects of using AACR. If the relationship between the facilitator and instructors was not positive, it is unlikely instructors would wish to join. Fortunately, instructors said they held their facilitators in high regard, and many described that relationship as the primary reason for their initial participation. Elaine described her facilitator as the reason she decided to join in the first place:

Elaine: I mean we've interacted with [facilitator] forever, and her input to our teaching has been really beneficial because she's so invested in science education and she knows a lot. She's got a lot of experience with what works and what doesn't work. And we've done many studies with her, so it's a good relationship. We probably wouldn't do [the AACR group] without her; we wouldn't be able to. We need her.

Patrick had the experience of coteaching with his facilitator and cited her as a major influence on how he thinks about teaching now:

Patrick: I think that, again, going back to my experience with co-instructing with [facilitator] was one of the more impactful things in terms of changing my approach to teaching.

This impactful relationship likely contributed to Patrick's acceptance of the offer to participate in the AACR project when he was invited. 
Kate also described her facilitator as the driving force for her participation:

Kate: I really think the stimulus for [participation] is [facilitator], because [she's] gotten me involved [in the past]... I don't think I would probably initiate it because I've got such a good person here.

AACR Group Meetings Provide a Sense of Camaraderie. Although the relationship between the instructor and the facilitator played an important role in recruitment, the group dynamic of AACR groups was often cited as important for persistence. Many instructors also commented on the general sense of camaraderie they felt when attending the AACR group meetings. When Laura was asked how the AACR group meetings were going in year 2 interviews, she started out talking about how much she likes the group:

Laura: I think [the AACR group has] gone really well. One, I just like the group of people in terms of the group that [facilitator] put together here.

Hannah talked about the general sense of belonging she feels with her colleagues because they get along well and teach the same students:

Hannah: We work with the same group of students so we have a lot in common. We're all interested in seeing how each of these challenges works out for us and for the students.

Administrators Add Value to AACR Groups. At two of the AACR institutions, administrators participate in AACR groups. In both cases, the administrators regularly teach and use AACR questions. These administrator-participants often cited their role at the university as enabling them to bring a broader perspective to the groups compared with other participants whose university roles are more narrowly focused. Ryan discussed how his participation in the AACR group meetings could serve as an example to others:

Ryan: Yeah for sure, and the other thing that helps me is that I can help other people. So my other role is as head of department I interact with everyone in the department about their teaching. So, you know, lead from the front. I'm trying new things, maybe you could try new things. So that can only be good for the department, so it has an effect well beyond just me.

The other participants also recognized the value of the administrators' perspective. When Daniel was asked about the impact his fellow AACR group members were having on him, he noted the benefit of having an administrator present:

Daniel: They all have had a big impact but in different ways ... Another because they are bringing an administrative view that most instructors don't really think of. I mean each person has helped and made me think about things a lot in different ways.

\section{Without AACR Groups, Instructors Might Never Talk with Colleagues about Teaching}

The AACR project was designed to support instructors to use AACR in order to gain insights into student ideas and modify their teaching accordingly. As described earlier, we have evidence that this is part of the instructors' experience. However, our analyses also reveal that the most essential value of AACR group meetings stems from the unique space and time devoted to talking about teaching, which provides opportunities for conversations that go far beyond using AACR. Most faculty attend national meetings to discuss their research and do not shy away from talking with their colleagues about issues related to their research labs. Many instructors in our study, even those with primarily teaching appointments, have engaged infrequently in similar discourse about teaching. The supportive and private environment of AACR group meetings allows for conversations about teaching that might not happen in a hallway and articulation of teaching ideas that might have never been voiced. For example, Josh explained that, even though his AACR group consists of people he already knew, having the meetings has provided a dedicated space for teaching conversations:

Josh: Well, I mean [the AACR group is] an established group of folks that are interested in teaching and teach large classes, and it's a time for us. I mean, these are all people I know. I didn't meet anybody new. It's nice to have a continued, carved out space for us to keep contact with each other so that we can see what other folks are doing.

Similarly, Allison described how difficult it is to make time to talk about teaching, but that once the AACR group meeting is on her calendar, she is happy to have the opportunity:

Allison: So I think those discussions [about teaching] are always really, really great. They're hard to make time for because we all have very busy schedules, but once they're scheduled and they're just on your calendar ... you're going to go to it.

Brad described how difficult it is to make time to meet with his fellow teachers and explained that he enjoys the AACR group meetings because they give him a chance to interact with colleagues who teach similar classes:

Brad: I look forward to those meetings. They are really interesting. It's good to just meet with them because we're all so busy, we don't ever have a chance to go get a cup of coffee or anything. So it's just nice to see them. I always learn a lot, too, because we have the same size classes, different material that somewhat overlaps. Those guys have a lot of experience. We all have a lot of experiences, but we still hear something new from them just about every time. We discuss a lot of common issues.

The value of conversations about teaching ranged from general to specific. Within this theme, we found the following subcategories: 1) AACR groups help instructors feel like they are not alone in facing teaching challenges, 2) AACR groups provide a place to discuss a specific course, and 3) instructors get ideas for classroom activities during AACR group meetings (Table 1).

AACR Groups Help Instructors Feel Like They Are Not Alone in Facing Teaching Challenges. During the interviews, 
instructors often talked about aspects of teaching they found frustrating, and for many of our participants, AACR groups provide a way to cope. Samantha especially talked about the role her group fills in lightening the sense of hopelessness that teaching challenges can create:

Samantha: I put a lot of time and effort into teaching and sometimes when I don't see gains in student learning or I feel that the students aren't ... let's see ... I guess just trying as hard as I think they should be. It becomes frustrating and that can lower my morale. I won't stop trying because it's not in me to stop trying but I feel a little bit re-energized after I leave the [AACR group] meetings that okay, yeah, I'm not the only one that's feeling like this and we've just got to keep plugging away because this is a hard prospect. Improving teaching and learning is a challenging prospect and we shouldn't have to do it alone. We don't do scientific research alone, so talking about these things and sharing ideas is important. I just feel better. I just walk out feeling a little bit better about what I'm doing.

Brad is very thankful for the support he receives from his AACR group meetings. He values interacting with colleagues who teach classes similar to his and are therefore primed to provide support:

Brad: Just touching base about, you know, with faculty who are in the same situation with these big intro classes. You're going to have some of the same logistical problems. We all deal with infrastructure and all the same set of issues, administration and all that, so it's just good to know that you're not alone dealing with these issues and also with trying to get your learning objectives across to the students and talking about ways to do that.

Kate also appreciates the supportive nature of her AACR group. When asked about the benefits she anticipated receiving from participating in the AACR project, she replied:

Kate: Support for changing things, support for dealing with problems, thinking about how this isn't working, how do I need to change that?

AACR Groups Provide a Place to Discuss a Specific Course. It is well known that most university instructors do not regularly meet with other members of their department or unit who teach the same or a related course. Several of our participants expressed appreciation for their AACR groups because the groups provide a mechanism to have conversations that need to happen but typically do not. Kyle reported that, while sharing materials among colleagues is somewhat normal, regular meetings are not. His AACR group solved this problem:

Kyle: We all use the same book, we've all seen each others' syllabi and that type of thing, but we don't get together and talk all that often.

Brad related his experience with having difficulty connecting with instructors who teach other sections of the introductory biology sequence at his institution. He felt that the AACR group bridges that gap:
Brad: Just kind of to know if that other course is on the same page and to be aware that we're all doing this and there's [this] ability to touch base there as we go forward with [the AACR group meetings].

Claire recognized how difficult it can be to teach large introductory classes and appreciated the conversations about student ideas she was able to have with her AACR group:

\begin{abstract}
Claire: I think it's just good to even interact with people who are teaching lower-level classes on a regular basis and to see how misconceptions are seen in multiple classes, discuss patterns of how those sorts of things occur, and also how you kind of address some of them, and also just even how these different topics are sometimes explained.
\end{abstract}

Instructors Get Ideas for Classroom Activities during AACR Group Meetings. With AACR reports, instructors can identify challenges in student understanding and proceed to the next logical step: devising a way to address the scientifically inaccurate ideas expressed by their students. However, many instructors struggle to develop activities that hold students' interest and lead to improved student learning. Samantha greatly appreciated learning from her colleague how he had addressed scientifically inaccurate ideas in his class, especially because they both had used the same AACR question in their courses:

Samantha: [T]here was one meeting I specifically found useful. So [AACR colleague] had used the same question I used, and then he showed the example of the activity he had asked students to do that was aligned with this assessment. And it was a fantastic activity, and I thought it was so cool. And it was really useful for me to hear about what he had done.

Several instructors participated in a virtual community of practice, developing an activity addressing student misconceptions about the central dogma that were revealed by an AACR question (Pelletreau et al., 2016). Liz, who did not participate directly in the development, was able to observe the classroom activity through a colleague in her AACR group. She valued this contribution to her teaching:

Liz: Well for instance that activity, it was this little package thing that came to me. When I went through it, I thought, "Oh this is really good." So I took the time out, and it didn't take me very long... I didn't have to develop it myself, and it was a good [activity]. So it makes it easier.

\section{Instructors Worry about Spending Time Participating in Teaching Professional Development}

We have illustrated that participants valued being part of AACR groups. However, nearly all instructors also spoke of the reality of time constraints that influences the extent to which they engage in teaching professional development. They reported that they do not have ample time for teaching professional development and that they are unwilling to commit to a time-consuming opportunity even if participation has value (Table 1). For example, Brad admitted that, because of busy schedules, he and his colleagues will not seek opportunities for 
teaching professional development; for it to happen, teaching professional development must be easily accessible:

Brad: Right. Yeah, we're all busy, so we're not going to seek [teaching professional development opportunities] out. It has to be ... made available and made easier for us to access.

Andrew described in detail the many commitments that prevent him from fully engaging in the AACR project:

Andrew: So, I mean, of all the participants [in my AACR group], I'm probably the least active one... I'm swamped in the Fall. I've got three courses, 30 grad students [TAs] to oversee, 1000 [undergraduate] students, and AACR comes in at the bottom of the priority list.

We do not doubt that our participants, like all instructors, are busy but will invest considerable time in the parts of their job they consider to be a priority. Our instructors perceive that teaching-related activities are not valued at their research-intensive institutions. When asked about the general level of participation in teaching-related professional development in her department, Elaine, who has a primarily teaching appointment, responded that participation in teaching-related professional development skews toward teaching faculty. She first acknowledged that, while everyone generally cares about teaching, the research faculty do not tend to devote their time to changing their teaching:

Elaine: We care about undergraduate education; everyone in the department cares. It's on the radar screen, and it's not something that nobody ever talks about. It's just that the ability to devote time that you would need to change the way that you teach, the people that are involved in research and grant writing and all of that, they just don't have the time; or they choose not to use that time to do that. So they teach the way they teach without doing big changes ... Not because they don't care. It's because they perceive that they don't have the time.

Likewise, Daniel discussed how the reward system at a research-intensive institution discourages faculty from spending time improving their teaching:

Daniel: You can do a fantastic job coming up with organizing, "Okay this is what I want students to do." And you're not recognized in any way. If anything, you're punished because that took time away from when you could have actually maybe gotten further along on a paper or submitted one more grant or something like that, so ...

Matt, a participant with an active research lab, believes that his department holds a negative view of taking time to improve one's teaching:

Matt: There is no career benefit [to] improving your teaching ... there are a lot of disincentives to do that, like go into threeday workshop or something. In those three days you're not doing research. So you're actually-it actively hurts you to improve your teaching.
Given the perception of our participants that they should limit the time they spend on teaching professional development, why is it that they have persisted in a teaching-related professional development project for 2.5 years? Our instructors perceive that the time commitment for AACR groups is relatively low, so the value (described in previous sections) exceeds the cost. For example, as a faculty member with a research appointment, Jessica reported making choices to wisely invest the time she spends on teaching and, thus, away from research. She expressed the perception that the value she gets from participating in the AACR group far outweighs the cost:

Jessica: Oh, yeah. As I said, I find it a big bang for my buck so it's worth it, as far as I'm concerned, yes. They are very efficient. Our meetings are good. They don't take a huge amount of time, and I learn a lot. So that's good.

Ryan, an administrator, researcher, and teacher, cites the low time commitment as the reason he is even able to participate in the first place:

Ryan: I just simply don't have the time to commit to formal meetings and so on. This one has been good because it forces me to do that, but it's only once a month and it's only for an hour and it actually works...

Interviewer: So the [AACR group] seems like it's filling a real need for you?

Ryan: Absolutely. Because it's scheduled to my time, rather than me scheduling to its time.

\section{DISCUSSION}

The aim of this research was to explore the factors contributing to instructors' motivation to persist in a long-term, teaching professional development program supported by the AACR project. This topic of motivation to persist in such programs is generally understudied in education research (Stenfors-Hayes et al., 2010; Bouwma-Gearhart, 2012a,b; Sabagh and Saroyan, 2014). We have provided a rich description of the motivations of 19 college biology instructors over the course of the first 2.5 years of a 5-year study. Our overarching finding is that instructors enjoy participating in AACR groups, and this enjoyment helps them persist. This finding is elaborated through the following themes: AACR groups facilitate instructor involvement with AACR; AACR group dynamics encourage persistence; without AACR groups instructors might never talk with colleagues about teaching; and instructors worry about spending time participating in teaching professional development. We discuss in this section how our results may be used to facilitate high motivation for persistence in other teaching professional development programs. We also present a tailored EVT model as it applies to instructor motivation for teaching professional development.

\section{Instructors Need Support in Order to Adopt New Instructional Tools}

It is widely accepted that instructors need support in order to adopt new instructional practices (Henderson et al., 2011; Bouwma-Gearhart, 2012a; Andrews and Lemons, 2015); even in a best-case scenario with high levels of support, not all 
instructors are able to change their teaching approach (Henderson, 2005). Therefore, we were not surprised that the majority of our participants cited the AACR group and its support as a reason they were able to participate in the AACR project. Using AACR questions appropriately is a complex task, and all participants were unfamiliar with the tool when the project began. The instructors needed assistance to learn how to ask questions of their students, submit data, read the reports, and make meaning of the student data. The number of instructors in our study citing AACR groups as the main reason they sustained use of AACR assessments has important implications. As educators develop new instructional tools, we must keep in mind that instructors will need support to implement those tools correctly.

The appropriate level of support may vary. In AACR groups, the meetings during the first year were heavily focused on helping the instructors learn to use and manage AACR questions and reports; in later semesters, the meeting topics shifted toward general discussions about teaching. A teaching innovation with a learning curve similar to AACR may only need intense support for one or two semesters. Still, our data corroborate the findings of others (Henderson et al., 2011; Bouwma-Gearhart, 2012a,b; Andrews and Lemons, 2015) that support is necessary in some capacity for instructors to adopt and sustain use of new educational tools.

\section{Instructors Want to Discuss Teaching with Their Colleagues, but Often Do Not Find the Opportunities to Do So}

It has long been reported that faculty have a vast support network concerning their research but that teaching often is considered a solo endeavor (Baker and Zey-Ferrell, 1984). One of the goals of teaching professional development in general is to combat this line of thinking and provide a support network oriented toward teaching (e.g., Cox, 2001). Our findings show that instructors receive such support from the AACR groups. In a recent study of colleague-colleague interactions at one large research university, more than $60 \%$ of survey respondents said they did not talk about teaching with departmental colleagues once per week, and roughly one-third of the participants did not have those interactions even once per month (Andrews et al., 2016). Our data suggest that this pattern of not discussing teaching with colleagues may be common at research-intensive universities. However, we also found that instructors value conversations with their colleagues about teaching. Taken together, these findings indicate that the reason discussions about teaching do not occur regularly is not that instructors do not want to have them.

If we consider that faculty want to discuss teaching with their colleagues, but they regularly do not, we can hypothesize that a teaching professional development program that fosters conversations would be perceived to fill an unmet need. Indeed, persistence in AACR groups is partially owed to this very idea: participants regularly reported they did not frequently talk about teaching, and yet they relished opportunities to do so. Environments that promote teaching discussions may provide instructors with access to otherwise unavailable social networks. These networks may lead to weak social ties, which are of great importance for the spread of novelty, for example, novel teaching information, assessments, or curricula (Granovetter, 1973; Tenkasi and Chesmore, 2003; Quardokus and Henderson, 2014). Additionally, if instructors spend extended amounts of time together and invest in one another emotionally, strong social ties may develop, which are critical for the transfer of complex and detailed knowledge, for example, how to lead a classroom activity to address student misconceptions (Granovetter, 1973; Tenkasi and Chesmore, 2003; Quardokus and Henderson, 2014).

\section{Finding a Balance between Time Investment and Persistence}

There are many barriers that can prevent instructors from participating in teaching professional development, with lack of time as a primary factor cited in previous research (Henderson and Dancy, 2008; Stenfors-Hayes et al., 2010; Sabagh and Saroyan, 2014; Andrews and Lemons, 2015). Likewise, time limitations were mentioned by nearly all of our participants. With AACR groups, instructors were asked to spend approximately 3 hours per semester in a meeting, with a maximum of one additional hour per semester to participate in research via surveys and interviews. Additionally, facilitators scheduled each meeting according to participants' schedules. We propose that the efforts of the facilitators to keep the time investment low and the meetings convenient led to high expectancy and low cost among participants.

We currently do not know how much time spent in teaching professional development is too much to ask of an instructor. At what level of time commitment would we begin to see attrition? Despite the finding that maintaining a low time commitment is important to sustained participation in an AACR group, we suspect that instructors would benefit from more time spent in teaching professional development. For example, members could be encouraged to complete reciprocal observations of one another's courses; this could be done on a day when a participant is discussing AACR data with students or using an AACRrelated activity in class. Concrete feedback on one's teaching is valuable to many instructors and has been shown to be critical in changing one's teaching (Henderson et al., 2011), yet most instructors do not receive feedback outside of student evaluations (Gormally et al., 2014). Reciprocal course observations would increase the time commitment by only 1 to 2 hours per semester, which may be below the threshold at which many instructors would cease participating. Perhaps this small increase in time costs still would be offset by the value of participation. The question of how much teaching professional development time is enough and how much is too much should be actively explored in the AACR project and other teaching professional development initiatives.

\section{Benefits of Joining a Teaching Professional Development Activity}

In the case of the AACR groups, we found that most instructors perceived two major incentives for their initial agreement to participate. First, instructors perceived that AACR group participation would provide increased interaction with the facilitator. If an instructor wishes to begin a similar teaching professional development project at his or her institution but does not have the larger goal of working on a project of national scale, like AACR, our data suggest that he or she can still be successful, as respect for the facilitator was paramount among our participants. On the basis of our data, we hypothesize that any instructor who is well respected by his or her colleagues could build and sustain a faculty group focused on teaching (assuming time 
commitments are kept low). We propose that more instructors who are interested in increasing the attention paid to teaching in their departments and institutions instigate our model as a starting point for change.

Second, instructors perceived that

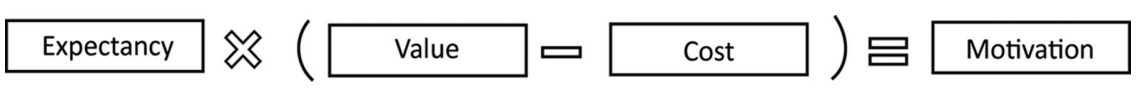

FIGURE 4. Simplified EVT model. Schematic depicting our understanding of the EVT model as it applies to instructor motivation, depicting the relationships among expectancy, value, and cost.

AACR group participation would provide access to AACR as a tool to understand student ideas, providing a second incentive for instructors to join the project. Many instructors are dissatisfied with multiple-choice assessments, and with good reason. Multiple-choice assessments are not the best tool for exploring students' complex understandings of the biological world (Nehm and Schonfeld, 2008; Stanger-Hall, 2012). Yet in large classes with little support for grading, they are the most efficient way to evaluate students. A desire for better assessment tools, whether formative or summative, was a concern expressed by many of the participants throughout both sets of interviews. Initially, some instructors joined the project with the hope of eventually using AACR to help grade student answers. We informed these instructors early on that AACR questions were intended for formative, not summative, assessment, and they still found value in using AACR as an instructional tool. On the basis of our data, we propose that providing assessment resources was a key hook to entice instructors to participate in the AACR groups. All instructors must assess students, and many are dissatisfied with their assessment methods. Teaching professional development opportunities built around this challenge could offer a magnet for instructor participation.

Regarding incentives, we cannot ignore the fact that AACR group participants received money for participating in the research associated with participation (see Methods). It is possible that money has influenced persistence. However, we did not investigate this factor, and instructors never spontaneously referred to money as an incentive. Thus, we cannot comment on its impact.

\section{Applying the EVT Model to Instructor Motivation}

In a recent study, Finelli and colleagues used the EVT to understand what factors would encourage engineering faculty to adopt more effective teaching practices (Finelli et al., 2014). They found a tight correlation between the two expectancy factors proposed by Eccles and Wigfield: ability self-concept and task difficulty (Eccles, 1983; Wigfield and Eccles, 1992, 2000). Because of this correlation, they focused on the category of expectancy as a whole, rather than differentiating between the two factors. Our data also supported a single category for expectancy. We also found that dividing the concept of value into the subcategories of intrinsic, utility, and attainment values was difficult. It was common for an instructor to refer to all three aspects of the value category in a single description. As an example, in one instance of dialogue, an instructor would talk about enjoying the AACR group (intrinsic value) because it gave her a chance to talk about and improve teaching (utility), as well as improving teaching to improve job performance (attainment). However, instructors almost always discussed costs separately. Our findings support the idea that EVT can be applied to help explain instructor motivation, while considering cost as a separate subcategory of value (Figure 4).

In summary, we have detailed instructors' participation in the first 2.5 years of a 5-year longitudinal study of participants in AACR groups. While we have found persistence to be high, we are not claiming that participation in AACR groups has led to changes in participants' teaching. Indeed, we will explore participants' ideas about teaching and their teaching practices elsewhere; as others have shown, participation in teaching professional development does not necessarily indicate observable changes in one's teaching (Ebert-May et al., 2011). However, participation, and the motivation to persist in such programs, is a critical part of the change process. Perhaps sustained participation in teaching professional development provides the prioritization needed for instructors to decide to change their teaching or to remain in a cycle of changing their teaching (Andrews and Lemons, 2015). AACR groups may provide a forum for teaching professional development that instructors will engage in for years.

\section{ACKNOWLEDGMENTS}

This material is based on work supported by the National Science Foundation under grants DUE 1347733 and 1322962. Any opinions, findings, and conclusions or recommendations expressed in this material are those of the authors and do not necessarily reflect the views of the National Science Foundation. Additional support was provided by the University of Georgia. We thank the instructors who participated in this study. We also thank the Biology Education Research Group (BERG) at the University of Georgia, who improved the quality of this work with critical feedback on the article. We also thank the AACR Professional Development team for helpful feedback. Thank you to the monitoring editor and anonymous reviewers whose insights greatly improved the article.

\section{REFERENCES}

Addis, E. A., Quardokus, K. M., Bassham, D. C., Becraft, P. W., Boury, N., Coffman, C. R., ... Powell-Coffman, J. A. (2013). Implementing pedagogical change in introductory biology courses through the use of faculty learning communities. Journal of College Science Teaching, 43, 22-29.

American Association for the Advancement of Science. (2011). Vision and change in undergraduate biology education: A call to action. Washington, DC.

Andrews, T. C., Conaway, E. P., Zhao, J., \& Dolan, E. L. (2016). Colleagues as change agents: How department networks and opinion leaders influence teaching at a single research university. CBE-Life Sciences Education, 15, ar15.

Andrews, T. C., \& Lemons, P. P. (2015). It's personal: Biology instructors prioritize personal evidence over empirical evidence in teaching decisions. CBE-Life Sciences Education, 14, ar7

Andrews, T. M., Leonard, M. J., Colgrove, C. A., \& Kalinowski, S. T. (2011). Active learning not associated with student learning in a random sample of college biology courses. CBE-Life Sciences Education, 10, 394-405.

Atkinson, J. W. (1957). Motivational determinants of risk-taking behavior. Neuropsychology Review, 64, 359-372.

Baker, P. J., \& Zey-Ferrell, M. (1984). Local and cosmopolitan orientations of faculty: Implications for teaching. Teaching Sociology, 12, 82-106.

Battle, E. (1965). Motivational determinants of academic task persistence. Journal of Personality and Social Psychology, 2, 209-218. 
Battle, E. (1966). Motivational determinants of academic competence. Journal of Personality and Social Psychology, 4, 534-642.

Beach, A. L., \& Cox, M. D. (2009). The impact of faculty learning communities on teaching and learning. Learning Communities Journal, 1(1), 7-27.

Bouwma-Gearhart, J. (2012a). Research university STEM faculty members motivation to engage in teaching professional development: Building the choir through an appeal to extrinsic motivation and ego. Journal of Science Education and Technology, 21, 558-570.

Bouwma-Gearhart, J. (2012b). Science faculty improving teaching practice: Identifying needs and finding meaningful professional development International Journal of Teaching and Learning in Higher Education, 24, $180-188$.

Charmaz, K. (2006). Constructing grounded theory: A practical guide through qualitative analysis. London: Sage.

Clark, M. C., Froyd, J., Merton, P., \& Richardson, J. (2004). The evolution of curricular change models within the foundation coalition. Journal of Engineering Education, 93, 37-48.

Cox, M. (2001). Faculty learning communities: Change agents for transforming institutions into learning organizations. To Improve the Academy, 19 (69-93).

Cox, M. D. (2003). Fostering the scholarship of teaching and learning through faculty learning communities. Journal on Excellence in College Teaching, 14, 161-198.

Cox, M. D. (2004). Introduction to faculty learning communities. New Directions for Teaching and Learning, 97, 5-23.

Dancy, M., \& Henderson, C. (2007). Framework for articulating instructional practices and conceptions. Physical Review Special Topics-Physics Education Research, 3, 010103.

Davidovitch, N., \& Soen, D. (2006). Using students' assessments to improve instructors' quality of teaching. Journal of Further and Higher Education, 30(4), 351-376

Deci, E., \& Ryan, R. (1985). Intrinsic motivation and self-determination in human behavior. New York: Pantheon.

Ebert-May, D., Derting, T. L., Hodder, J., Momsen, J. L., Long, T. M., \& Jardeleza, S. E. (2011). What we say is not what we do: Effective evaluation of faculty professional development programs. BioScience, 61, 550558.

Eccles, J. S. (1983). Expectancies, values, and academic behaviours. In Spence, J. T. (Ed.), Achievement and achievement motivation (pp. 75-146). San Francisco, CA: Freeman.

Eccles, J. S. (2005). Subjective task value and the Eccles et al. model of achievement-related choices. In Elliot, E. J., \& Dweck, C. S. (Eds.), Handbook of competence and motivation (pp. 105-121). New York: Guilford.

Eccles, J. S., Adler, T., \& Meece, J. L. (1984). Sex differences in achievement: A test of alternate theories. Journal of Personality and Social Psychology. $46,26-43$

Eddy, S. L., \& Hogan, K. A. (2014). Getting under the hood: How and for whom does increasing course structure work? CBE-Life Sciences Education, 13, 453-468.

Elliott, E. R., Reason, R. D., Coffman, C. R., Gangloff, E. J., Raker, J. R., Powell-Coffman, J. A., \& Ogilvie, C. A. (2016). Improved student learning through a faculty learning community: How faculty collaboration transformed a large-enrollment course from lecture to student centered. CBE-Life Sciences Education, 15, ar22.

Finelli, C. J., Daly, S. R., \& Richardson, K. M. (2014). Bridging the research-to-practice gap: Designing an institutional change plan using local evidence. Journal of Engineering Education, 103, 331-361.

Finelli, C. J., \& Millunchick, J. M. (2013). The teaching circle for large engineering courses: A cohort-based model for faculty development. Paper presented at: 2013 ASEE Annual Conference and Exposition: (Atlanta, GA).

Fixsen, D. L., Naoom, S. F., Blase, K. A., Friedman, R. M., \& Wallace, F. (2005). Implementation research: A synthesis of the literature (Louis de la Parte Florida Mental Health Institute Publication 231). Tampa: University of South Florida, National Implementation Research Network.

Freeman, S., Eddy, S. L., McDonough, M., Smith, M. K., Okoroafor, N., Jordt, H., \& Wenderoth, M. P. (2014). Active learning increases student performance in science, engineering, and mathematics. Proceedings of the National Academy of Sciences USA, 111, 8410-8415.
Gallos, M. R., Berg, E. V. D., \& Treagust, D. F. (2005). The effect of integrated course and faculty development: Experiences of a university chemistry department in the Philippines. International Journal of Science Education, 27, 985-1006

Gibbs, G., \& Coffey, M. (2004). The impact of training of university teachers on their teaching skills, their approach to teaching and the approach to learning of their students. Active Learning in High Education, 5, 87-100.

Glaser, B. G., \& Strauss, A. L. (1967). The discovery of grounded theory: Strat egies for qualitative research. Chicago, IL: Aldine.

Gormally, C., Evans, M., \& Brickman, P. (2014). Feedback about teaching in higher ed: Neglected opportunities to promote change. CBE-Life Sciences Education, 13, 187-199.

Granovetter, M. S. (1973). The strength of weak ties. American Journal of Sociology, 78(6), 1360-1380.

Ha, M., Nehm, R. H., Urban-Lurain, M., \& Merrill, J. E. (2011). Applying computerized-scoring models of written biological explanations across courses and colleges: Prospects and limitations. CBE-Life Sciences Education, 10, 379-393.

Handelsman, J., Miller, S., \& Pfund, C. (2007). Scientific teaching. Macmillan.

Hannan, A. (2005). Innovating in higher education: Contexts for change in learning technology. British Journal of Educational Technology, 36, 975985.

Haudek, K. C., Kaplan, J. J., Knight, J., Long, T., Merrill, J., Munn, A., .. Urban-Lurain, M. (2011). Harnessing technology to improve formative assessment of student conceptions in STEM: Forging a national network. CBE-Life Sciences Education, 10, 149-155.

Haudek, K. C., Prevost, L. B., Moscarella, R. A., Merrill, J., \& Urban-Lurain, M. (2012). What are they thinking? Automated analysis of student writing about acid-base chemistry in introductory biology. CBE-Life Sciences Education, 11, 283-293.

Henderson, C. (2005). The challenges of instructional change under the best of circumstances: A case study of one college physics instructor American Journal of Physics, 73, 778-786.

Henderson, C., Beach, A., \& Finkelstein, N. (2011). Facilitating change in undergraduate STEM instructional practices: An analytic review of the literature. 48, 952-984

Henderson, C., \& Dancy, M. H. (2008). Physics faculty and educational researchers: Divergent expectations as barriers to the diffusion of innovations. American Journal of Physics, 76, 79.

Howland, J., \& Wedman, J. (2004). A process model for faculty development: Individualizing technology learning. Journal of Technology and Teacher Education, 12, 239-263.

Krockover, G. H., Shepardson, D. P., Adams, P. E., Eichinger, D., \& Nakhleh, M (2002). Reforming and assessing undergraduate science instruction using collaborative action-based research teams. School Science and Mathematics, 102, 266-284.

Lynd-Balta, E., Erklenz-Watts, M., \& Westbay, T. D. (2006). Professional development using an interdisciplinary learning circle. Journal of College Science Teaching, January/February, 18-24.

Marbach-Ad, G., Ziemer, K. L. S., Thompson, K. V., \& Orgler, M. (2013). New instructor teaching experience in a research-intensive university: implications for professional development. Journal on Centers for Teaching and Learning, 5, 49-90.

Matusovich, H. M., Paretti, M. C., McNair, L. D., \& Hixson, C. (2014). Faculty motivation: A gateway to transforming engineering education. Journal of Engineering Education, 103(2), 302-330.

McClelland, D. C., Atkinson, J. W., Clark, R. A., \& Lowell, E. L. (1954). The achievement motive. New York: Appleton-Century-Crofts

McShannon, J., Hynes, P., Nirmalakhandan, N., Venkataramana, G., \& Ricketts, C. (2006). Gaining retention and achievement for students program. $132,204-208$

Moharreri, K., Ha, M., \& Nehm, R. H. (2014). EvoGrader: An online formative assessment tool for automatically evaluating written evolutionary explanations. Evolution: Education and Outreach, 7(1), 15

Nagengast, B., Marsh, H. W., Scalas, L. F., Xu, M. K., Hau, K-T., \& Trautwein, U. (2011). Who took the " $x$ " out of expectancy-value theory? A psychological mystery, a substantive-methodological synergy, and a cross-national generalization. Psychological Science, 22, 1058-1066. 
National Research Council (NRC). (2003). BIO 2010: Transforming undergraduate education for future research biologists. Washington, DC: National Academies Press.

NRC. (2012). Discipline-based education research. Washington, DC: National Academies Press.

Nehm, R. H., \& Schonfeld, I. S. (2008). Measuring knowledge of natural selection: A comparison of the CINS, an open-response instrument, and an oral interview. Journal of Research in Science Teaching, 45, 11311160.

Oleson, A., \& Hora, M. T. (2014). Teaching the way they were taught? Revisiting the sources of teaching knowledge and the role of prior experience in shaping faculty teaching practices. Higher Education, 68, 29-45.

Patton, M. Q. (2014). Qualitative evaluation and research methods. Newbury Park, CA: Sage.

Pelletreau, K. N., Andrews, T., Armstrong, N., Bedell, M. A., Dastoor, F., Dean, N., Erster, S., Fata-Hartly, C., Guild, N., Greig, H., Hall, D., Knight, J. K., Koslowsky, D., Lemons, P. P., Martin, J., McCourt, J., Merrill, J., Moscarella, R., Nehm, R., Northington, R., Olsen, B., Prevost, L., Stoltzfus, J., Urban-Lurain, M., \& Smith, M. K. (2016). A clicker-based study that untangles student thinking about the processes in the central dogma. CourseSource. doi: $10.24918 / \mathrm{cs} .2016 .15$

Penberthy, D. L., \& Millar, S. B. (2002). The "hand-off" as a flawed approach to disseminating innovation: Lessons from chemistry. Innovative Higher Education, 26, 251-270

Porter, A. L., Roessner, J. D., Oliver, S., \& Johnson, D. (2006). A systems model of innovation processes in university STEM education. Journal of Engineering Education, 95, 13-24.

President's Council of Advisors on Science and Technology. (2012). Engage to excel: Producing one million additional college graduates with degrees in science, technology, engineering, and mathematics. Washington, DC: U.S. Government Office of Science and Technology. Retrieved August 5, 2017, from http://eric.ed.gov/?id=ED541511

Prevost, L. B., Smith, M. K., \& Knight, J. K. (2016). Using student writing and lexical analysis to reveal student thinking about the role of stop codons in the central dogma. CBE-Life Sciences Education, 15(4), ar65. doi:10.1187/cbe.15-12-0267

Pundak, D., \& Rozner, S. (2007). Empowering engineering college staff to adopt active learning methods. Journal of Science Education and Technology, 17, 152-163.

Quardokus, K., \& Henderson, C. (2014). Using department-level social networks to inform instructional change initiatives. Proceedings of the NARST 2014 annual meeting, April 1, 2014 (Pittsburgh, PA).

Rushin, J. W., De Saix, J., Lumsden, A., Streubel, D. P., Summers, G., \& Bernson, C. (1997). Graduate teaching assistant training: A basis for improvement of college biology teaching $\&$ faculty development? American Biology Teacher, 59, 86-90.

Sabagh, Z., \& Saroyan, A. (2014). Professors' perceived barriers and incentives for teaching improvement. International Education Research, 2(3), 18 30.

Saldaña, J. (2013). The coding manual for qualitative researchers. Thousand Oaks, CA: Sage.

Schwandt, T. A. (2007). The SAGE dictionary of qualitative inquiry. Thousand Oaks, CA: Sage

Sirum, K. L., \& Madigan, D. (2010). Assessing how science faculty learning communities promote scientific teaching. Biochemistry and Molecular Biology Education, 38, 197-206.

Stanger-Hall, K. F. (2012). Multiple-choice exams: An obstacle for higher-level thinking in introductory science classes. CBE-Life Sciences Education, 11, 294-306.

Stenfors-Hayes, T., Weurlander, M., Dahlgren, L. O., \& Hult, H. (2010). Medical teachers' professional development-Perceived barriers and opportunities. Teaching in Higher Education, 15(4), 399-408.

Strauss, A., \& Corbin, J. (1998). Basics of qualitative research. London: Sage.

Suddaby, R. (2006). From the editors: What grounded theory is not. Academy of Management Journal, 49, 633-642.

Tenkasi, R. V., \& Chesmore, M. C. (2003). Social networks and planned organizational change: The impact of strong network ties on effective change implementation and use. Journal of Applied Behavioral Science, 39(3), 281-300.

Urban-Lurain, M., Cooper, M. M., Haudek, K. C., Kaplan, J. J., Knight, J. K., Lemons, P. P., ... Sydlik, M. (2014). Expanding a national network for automated analysis of constructed response assessments to reveal student thinking in STEM. Paper presented at the 2014 ASEE Annual Conference and Exposition, Indianapolis, IN.

Walczyk, Jeffrey J., \& Ramsey, L. L. (2003). Use of learner-centered instruction in college science and mathematics classrooms. 40, 566584.

Weiss, T. H., Feldman, A., Pedevillano, D. E., \& Copobianco, B. (2003). The implications of culture and identity: A professor's engagement with a reform collaborative. International Journal of Science and Mathematics Education, 1, 333-356.

Weston, M., Haudek, K. C., Prevost, L. B., Urban-Lurain, M., \& Merrill, J. E. (2015). Examining the impact of question surface features on students answers to constructed-response questions on photosynthesis. CBELife Sciences Education, 14, ar19.

Wigfield, A., \& Eccles, J. S. (1992). The development of achievement task values: A theoretical analysis. Developmental Review, 12, 265-310.

Wigfield, A., \& Eccles, J. S. (2000). Expectancy-value theory of achievement motivation. Contemporary Educational Psychology, 25, 68-81. 